\title{
THE CHALLENGES OF MARKET RESEARCH IN CHINA
}

This article analyses the challenges of current market research activities in China. A country that achieved remarkable economic development since the late 1970s and that is still continuing to grow.

Firstly a picture of the market research industry in China is provided. Based on the history of market research, the leading companies and the most important types and aims of research are highlighted. The development of the market research industry in the framework of the Chinese market in general leads to challenges in primary and secondary research. Primary research in China is dominated by regional disparities, particularly in terms of language and culture. A continuous trend to urbanisation leads to a massive accumulation of individuals and enterprises in 'mega cities'. Even so, the challenge of providing solid data quality seems to be still considerable. On the other hand, secondary data is still lacking in many ways. The availability is still sporadic and the quality remains inadequate. Furthermore the validity in general appears to be questionable.

As discretionary income increases, the type and amount of products being consumed has changed significantly. Chinese customers are therefore confronted with a growing range of buying decisions. The rate of which the Chinese market is changing underlines the importance of research being up-to-date.

\section{Introduction}

In recent years China has become an important market for foreign investment. Overseas companies feel strongly attracted to China due to its strong economic growth and the size of its market. Since entering the World Trade Organisation, trades barriers have been reduced and new sectors of the economy have opened up to foreign firms [8, 15, 22]. As the result of rapid market growth and development, Chinese per capita gross domestic product (GDP) has quadrupled over the past two decades, growing at an annual average rate of $10 \%$. Apart from differences in purchasing power, China has emerged as the second largest economy in the world [19].

Notwithstanding the tremendous progress on economic reforms and modernisation, it is essential to understand that the Chinese market has many specifics making it challenging for foreign companies doing business there [22]. Moreover, reliable and comprehensive market information is important for accurate market evaluation and the development of successful marketing strategies. In order to occupy a leading position in a keen market, companies must understand Chinese market structures and specifics. They need information that can help them develop a clear picture of the market and avoid costly mistakes that might lead to inadequate strategies or lost opportunities [1]. Different challenges and obstacles must be overcome when gathering information in emerging markets like China. As Walters and Samiee (2003) and Trinh (2004) state, the lack of information is a key reason for the absence of planning activities in many developing markets [22]. In this regard,
China is no exception. In addition, the limited market transparency, the diversity of the country and the cultural and linguistic barriers complicate opportunities for collecting information and carrying out effective market research [21,23].

\section{The Chinese Market Research Industry}

With a history of about 25 years, the market research industry in China is relatively young. In 1979 with the start of the open policy in China, the requirements for a free market economy and market research were born. Research firms based in Hong Kong started their exploration of the Chinese market and carried out first market research projects. A few years later, the first stateowned consulting companies in mainland China emerged. Particularly since the Chinese economy has become more market orientated with increasingly discerning customers, the demand for market research services has increased and with it the number of market research companies has grown significantly [23].

The total number of market research agencies in China is uncertain. The Chinese Market Research Association (CMRA) quoted that over 1200 such companies are active in the country. This number includes medium and large-sized companies as well as smaller market research providers. The CMRA [27] classifies the market into seven tiers, according to the companies' turnover in China. AC Nielson, CTR (a joint venture between TNS and a state-owned research company CVSC) and CSM (a CTR subsidiary) achieved the highest turnover with close to $\$ 26.8$ million

\footnotetext{
* Lena Weick

Faculty of Economics, University of Applied Sciences Darmstadt, Germany, PhD-Student, Faculty of Operation and Economics of Transport and

Communications, University of Zilina, Slovakia, Email: lenaweick@web.de
} 
in 2006. Tier two and three includes many of the most famous companies in research like Research International, Synovate, Ipsos China and Sinotrust (a Chinese company) as well as GfK China, Gallup China, TNS, and Millward Brown. Most of the large agencies have an office in each of the three major cities: Beijing, Shanghai and Guangzhou.

Over the past years, some of those large general research companies have increased their business-to-business focus, and also foreign B2B research specialists have arrived in China. In terms of B2B research capabilities, two Chinese agencies are noteworthy: Sinomonitor and All China Market Research (ACMR). The latter is a subsidiary of the State Statistical Bureau of China and benefits from its access to legislators and regulators.

A high number of smaller Chinese research companies with a turnover less than 5 million RMB are largely provincial rather than based in Beijing, Shanghai and Guangzhou. Their research activities mainly focus on fieldwork to collect information outside the big cities, on behalf of larger agencies. Around half of the foreign research agencies are subsidiaries or joint ventures and provide full services including fieldwork and desk research. Most of their research is commissioned by western clients, together with a small number of Chinese clients. The latter are especially interested in conducting export studies in western countries, a trend that is expected to increase over time [9].

In 2006 the value of market research commissioned in China was worth about \$US 636.1 million. The market was growing at $20 \%$ per annum. With about $25-30 \%$ of the overall industry value the proportion of business-to-business research was relatively high. By contrast, the proportion of B2B research in the Western market amounts to $10 \%$ of the overall industry value. Large-scale business-to-business research is developing rapidly in China as foreign companies invest further in a better understanding of how they may enter new and expand current market audiences. Business-toconsumer research is already well developed in China with a wide range of international and domestic providers. While the Chinese market for consumer research was estimated to be growing at 17-18 \% per annum, the business-to-business research with a value of \$US50 million was even estimated higher, growing $25 \%$ per annum $[9,16]$.

The focus of market research in China differs from that in Europe and North America. In western countries research reflects the objectives of companies operating in mature markets wanting to e.g. monitor the satisfaction of their costumers; segment their target groups and establish customer loyalty. Therefore typical research projects are customer satisfaction studies, branding and segmentation studies. The clients generally seek information that will help them to progress in existing markets. Conversely, in China about $60 \%$ of research projects are focussed on market entry and market assessment studies, in which clients ask for information about market size and structure [9].

In terms of industry sectors in which organisations conduct most research, the level of commissioned research in 2006 can be ranked as follows: automotive, followed by petrochemical, infor- mation technology (IT), telecoms, pharmaceutical/ medical and finally financial [9].

The development of a marketing research infrastructure is comparably fast as is the Chinese market environment in general. The history of China's market research industry reveals that the sector is relatively young and has a fluctuating growth rate. Access and quality of information are still not the same as in western countries [26]. With the increasing spread of mobile radio and internet, the communication barriers between the economic centres have largely ceased, though this affects some western parts of China only in part [11]. China's research environment is changing and the quality of market research is improving. More and better information is available $[5,14,26]$, though challenges in producing data in China still arise. These are related to the implementation of primary research in China, as well as the identification and analysis of secondary sources.

\section{Secondary data availability, quality and validity}

"An identifying and analysing secondary data source is more of an art than a science." [16] As China is a growing economy, the identification and analysis of secondary sources is difficult yet critical in terms of the availability and reliability of information. A comparative approach of diverse sources seems most appropriate in order to maximise usefulness.

In the past, the availability of secondary data in China, was limited and it was hard to get hold of accurate and relevant market research information. Whereas in Western countries a wide variety of market intelligence is provided through industry associations or government agencies, in China less information is published [23]. But, during the last years, this situation has improved and more industries within China have at least one association providing information on industry activities. Usually, these associations are closely related to the government [12]. Harrison (2006) states: "For industry statistics and details of regulations, it is doubtful that any country makes more information available than China does." [9].

Historically collecting adequate data in China has not been facilitated by economic reforms. Before the reforms were introduced in the late 1970s, agricultural production was divided into communes. For these small production units, it was easy to collect the necessary data. The data was then passed through the ranks of the communist regime and collected at the highest level statistical bureau. However, with decollectivisation the rural economy became divided into much smaller segments. Additionally, the number of private enterprises and the number of self-employed workers increased. Services also entered the production structure. Thus, collecting adequate data became much more complex in the 1980s. China's National Bureau of Statistics (NBS) had to adjust to these changes, but only managed to do so gradually. Since opening the economy to the rest of the world in 1978, a lot of progress has been made in collecting data. The quality of Chinese data has improved significantly. Data falsification has been reduced, variables are more consistently defined and data is evaluated by a greater number of better-trained personnel [12]. Nowadays most indus- 
tries within China have at least one association providing information on industries activities. These associations are closely related to the government [9]

It is hard to get hold of market data. Access to such information is complicated by language issues, making desk research into Chinese markets a difficult task for western companies. Increasingly however, information is provided in English or other European languages [10]

Data quality and reliability secondary sources need to be analysed critically as "...secondary information [...] is often old, questionable, or inaccurate..." [16] Whether data is attained from the government itself, from research companies or from other organisations, much of it is actually governmental in origin. This means that secondary information is often compromised by a need to rely heavily on data that are reported by regional and local authorities. On a yearly basis, the National Bureau of Statistics (NBS) publishes the Statistical Yearbook of China. This is an important secondary source. Each province has its own Statistical Yearbook which does not necessarily contain the same information as the Yearbook of China. The yearbook figures are very often not up-todate. And because of political pressures to inflate performance, it is widely argued that most of the Chinese official statistics are inaccurate and figures are manipulated to the favour of provincial authorities [16, 22, 23].

\section{Primary research in the context of regional disparities, urbanisation and the challenge of data quality}

"Primary research is typically the most extensive, reliable, useful, time consuming, and costly. Though this is true anywhere in the world, it is especially true in China. Data that comes through primary research in China can be valuable, but it can also be incomplete, misleading or even false." [16]

This is caused by cultural differences as well as the geographic scale, size and diversity of the Chinese markets (with about 70 regions, 56 ethnical groups and more than 80 languages, the Chinese market is much more complex than the European market). It results in challenges of research capabilities and techniques. Because of disparities in economic development, purchasing power and cultural factors both between and within regions, attitudes and patterns of behaviour can vary sharply across mainland China and lead to differences in answers and in the interpretation of responses [22]. Knowing and understanding these differences will facilitate the research work [18].

Interviews are a good example of how to gain authentic information on the Chinese market [23]. But unlike western countries, company representatives are often hesitant to speak negatively of themselves or positively of their business competitors. Hence, interviewers must read between the lines and cross-check as much as possible (for example, to ask the same question two ways at different points in the interview). It is advisable to use mainland
Chinese interviewers for business research, as their sensitivity to cultural specifics enables them to communicate more effectively [16].

A great problem in conducting research in China is the language [26]. The language issue is compounded by the existence of various dialects that are somewhat similar but exist as separate entities. In terms of the script, different dialects are exactly the same, but the phonetic usage as well as the accent could affect the usage. Chinese characters can not simply be translated with a dictionary; moreover a native speaker should translate the words in consideration of the cultural traditions $[14,17,18]$. These differences could be approached by targeted primary research that is conducted differently for each region, for example with local research agencies or partners.

Besides cultural differences, country size and diversity, urbanisation is a special case in China [20]. Conducting research is easier in countries with a higher percentage of people living in urban areas. A higher degree of urbanization means that even if there are no good lists for sampling, the respondents can be contacted through other instruments. In economic theory, high growth rates and high urbanisation rates go hand in hand [5]. However, the experience in China has been different. Although the country has been continuously boasting high growth rates in 2005, the urban population only made up 43 per cent of the population [2]. Especially outside China's big cities, the level of infrastructure makes it hard to identify and select representative samples for survey research. Reliable and comprehensive lists that could form the basis for sampling frames are often not available and even when good sampling frames can be delineated, it is often necessary to obtain permission from the relevant authorities before collecting data [22]. On the other hand, the need for data from rural areas is questionable, especially in $\mathrm{B} 2 \mathrm{C}$ research. China shows an extreme inequality in income distribution. Besides overall inequality in general, the differences between rural and urban areas in particular should be considered when collecting market research data. The urban areas are likely to reach income (and consumption) levels comparable to developed countries, the widespread income distribution remaining in urban areas. On the other hand, the rural areas of China are still at the level of a developing country, with average incomes lower than $1 \$$ per day and consumption levels similarly low [3, 24]. Therefore, depending upon the aim of the research, a separation of approaches may be necessary between rural and urban areas.

\section{Conclusion}

In recent years, China's economy has undergone significant changes and continues to grow. It follows therefore, that China's research environment is also changing. The quality of market research is improving as more information is available. However, market research in China is dominated by dynamic and rapidly changing country specifics including language and culture. This leads to challenges in obtaining reliable, accurate, and up-to-date information on market conditions in China at micro and macro 
levels. Primary data collection and secondary research both have a number of advantages and limitations in China, particularly regarding costs, availability, reliability and appropriateness.

An important step for foreign companies wishing to effectively research projects in China is to examine the challenges of doing so. Firms should identify key regions of China and focus their research efforts on these areas. Moreover, they should choose partners for their market research who are familiar with the Chinese culture and ideally understand both the western and the Chinese business environments.

\section{References}

[1] BAI, F.; PING, G. (2004): Helping the Clients Succeed in China's B2B Market, ESOMAR Asia Pacific Conference, Shanghai 2004.

[2] BEIJING RUNDSCHAU (2008): China erlebt schnelle Urbanisierung (01.04.2008), Beijing, Retrieved August, 2008, from: http://www.bjrundschau.com/nachrichten/txt/2008_04/01/content_108401.htm

[3] BOROOAHA, V.K.; GUSTAFSSONB, B.; LIC, S. (2006): China and India: Income Inequality and Poverty North and South of the Himalayas, Journal of Asian Economics, Vol. 17, No. 5, pp. 797-817.

[4] BROCK, S. E. (1989): Marketing Research in Asia: Problems, Opportunities, and Lessons, Marketing Research, 9/1989, pp. 44-51.

[5] CRAIG, C.S.; DOUGLAS, S.P. (2005a): International Marketing Research, $3^{\text {rd }}$. edition, Chichester 2005.

[6] DATAMONITOR (Ed.) (2004): Market Research in China, Industry Profil, Retrieved June, 2008, from: http://www.marketresearch.com

[7] DIPPL-HENS, G.; ZENG, L. (2006): Konstruktive Einblicke - B2B Marktforschung in China, Research \& Results, Vol. 2, 2006, pp. 28-29.

[8] EBEL, B. et al. (2007): The Rise of the Dragon, Hofer, M. B.; Ebel, B. (Ed.): Business Success in China, Berlin 2007.

[9] HARRISON, M. (2006): Learning the Language, Marketing research, winter 2006, pp. 11-16

[10] HARRISON, M. (2006a): Business-to-Business Market Research in China, whitepaper, Retrieved 26. 08 . 2008 from http://www.b2binternational.com/library/whitepapers/whitepaper20.php

[11] HILGER, A. (2001): Erfolgsfaktoren fur Internationalisierungsstrategien - Dargestellt am Beispiel des Engagements deutscher Unternehmen in der VR China, Doctoral dissertation, Frankfurt amMain 2001.

[12] HOLZ, C. A. (2004): China's Statistical System in Transition: Challenges, Data Problems, and Institutional Innovations, Review of Income and Wealth, 50(3), 2002, pp 381-409.

[13] HUSSEN, H.-P.; MAURER, J. (2000): Marktforschung VR China/ Hongkong/ SVZ, Bundesagentur fur Außenhandelsinformationen (ed.), Koln, 2002.

[14] KUMAR, V. (Ed.) (2000): International Marketing Research, Upper Saddle River, New Jersey 2000.

[15] LIEBERTHAL, K.; LIEBERTHAL, G. (2004): The Great Transition, Harvard Business School Press: Harvard Business Review on Doing Business in China, Boston, 2004.

[16] OLIVER, C.; COULTER, J. E. (2004): China Market Research Strategies, China Business Review, May-June 2004, pp. 54-59.

[17] ROTHER, K. (1991): Das internationale Geschaft: Ziele, Marktforschung, Strategien, Marketing, Munchen 1991.

[18] SHENG, T. (2004): Understanding China - An automotive bamboo shoot, Proc. in ESOMAR Conference in Automotive Marketing 2004, Lausanne, 2004.

[19] SHENKAR, O. (2007): Chinas Jahrhundert, Munchen 2007.

[20] SMALL, K. A.: Chinese Urban Development: Introduction, Retrieved August, 2008, from: http://www.socsci.uci.edu/ ksmall/chineseurban.pdf

[21] TRINH, T. (2004): Foreign Direct Investment in China - good prospects for German companies? China Special, Deutsche Bank Research, Frankfurt 2004, Retrieved June, 2007, fromhttp://www.dbresearch.com

[22] WALTERS, P.; SAMIEE, S. (2003): Marketing Strategy in Emerging Markets: The Case of China, Journal of International Marketing, Vol. 11, 1/2003, pp. 97-106.

[23] WOLFF, B. (2007): Market Research as a Module in Market Strategies in China, Hofer, M. B.; Ebel, B. (Ed.): Business Success in China, Berlin 2007, pp. 151-167.

[24] WU, X.; PERLOFF, J. M. (2005): China's Income Distribution, 1985-2001; Retrieved August, 2008, from: are.berkeley.edu/ perloff/PDF/china.pdf

[25] YIXING, Z.; MA, L.J.C. (2003): China's Urbanization Levels: Reconstructing a Baseline from the Fifth Population Census, The China Quarterly, 173, 2003, pp. 176-196.

[26] ZABE-BRECHTEL, C. (2005): Marktforschung, Scharrer, B.; Neeff, U. (Eds.): So kommen Sie nach China - Der Wirtschaftswegweiser fur den Mittelstand, Munchen 2005.

[27] http://www.cmra.org.cu 